\title{
Entrevista ao arquiteto Egas José Vieira
}

\author{
João Caria Lopes \\ joaocarialopes@gmail.com \\ Atelier BASE | Centro de Estudos de Arquitetura, Cidade e Território da Universidade Autónoma \\ de Lisboa (CEACT/UAL), Portugal
}

Carlos Lemos Sequeira

carlos.lemos.sequeira@gmail.com

Arquiteto, Portugal

Para citação: LOPES, João Caria; SEQUEIRA, Carlos - Entrevista ao arquiteto Egas José Vieira. Estudo Prévio 18. Lisboa: CEACT/UAL - Centro de Estudos de Arquitetura, Cidade e Território da Universidade Autónoma de Lisboa, 2019, p. 2-13. ISSN: 2182-4339 [Disponível em: www.estudoprevio.net]. DOI: https://doi.org/10.26619/2182-4339/18.2

Creative Commons, licença CC BY-4.0: https://creativecommons.org/licenses/by/4.0/

\section{É com enorme prazer que temos como convidado o arquiteto e professor Egas José Vieira. Seja bem-vindo. Queríamos começar por perguntar como foi o seu percurso académico, como foi o seu curso de arquitetura e que professores e exercícios marcantes teve.}

Cheguei ao Departamento de Arquitetura da Escola de Belas-Artes (ESBAL/DA), no Chiado, em 1981, vinha do último ano do Propedêutico, que - como o nome indicia - era um ano de preparação para a universidade (no ano seguinte passou a chamar-se $12^{\circ}$ ano), as aulas eram dadas pela televisão, numa época em que ainda não existiam videogravadores e muito menos se "recuavam" as emissões televisivas.

Cheguei à escola, portanto, vindo de um ano um bocado desamparado. Não tinha a menor noção do que seria o ensino da arquitetura. Tinha apenas, isso sim, um bom apoio familiar, durante largos anos visitámos, nas férias dos meus pais, quase toda a Europa e quase todos os museus europeus mais importantes. Era algo a que em Portugal, não era habitual. De resto, como aluno, era mais um, normalíssimo. 


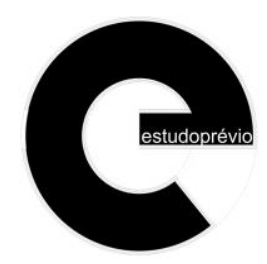

PT | E01 | EP18 | w2020

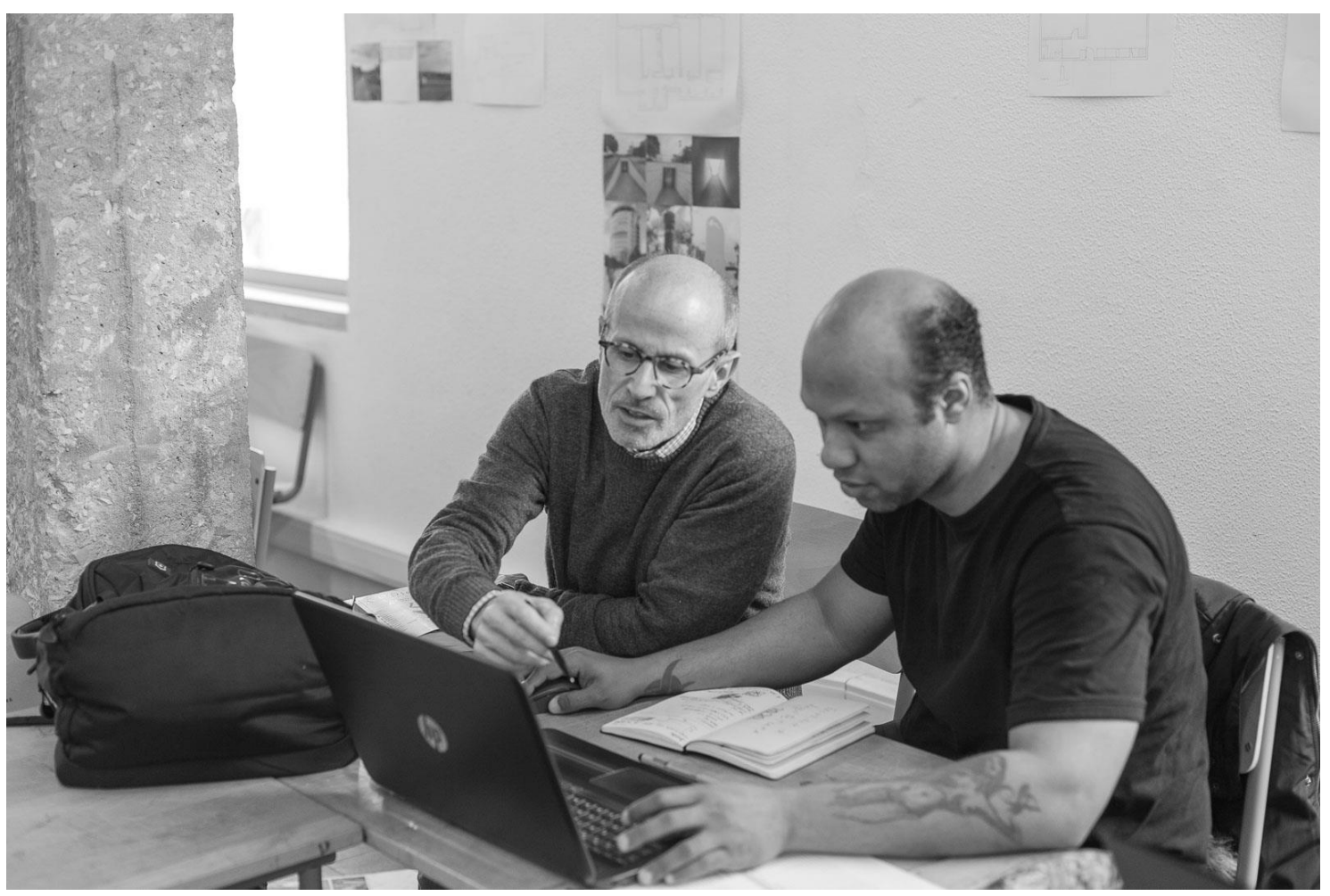

(c) Gonçalo Henriques + Estudo Prévio

Tive, no entanto, o enorme privilégio de ter tido o Arquiteto Frederico George como o meu primeiro Professor de Projeto (Carlos Lemonde de Macedo, era o assistente), foi o último ano em que ele deu aulas, para mim, o trabalho que foi desenvolvido ao longo desse ano constituiu uma enorme novidade.

De resto, penso que se passa exatamente o mesmo, com a grande maioria dos alunos de $1^{\circ}$ ano, quando chegamos à universidade, podemos ter (ou não ter de todo) uma ideia do que será a arquitetura, mas não sabemos muito bem como é que é feita, e sobretudo ensinada. Para mim foi um choque, principalmente em relação ao método pedagógico, porque os temas e as abordagens pareciam ser muito vagos e abertos, deixando espaço para a nossa reflexão, e não tão encaminhados e amparados como estava habituado no secundário.

Tudo foi sendo normal e naturalmente ultrapassado, nesse $1^{\circ}$ ano, tive as cadeiras habituais, Projeto (Frederico George), Construções (Dante de Macedo), Geometria Descritiva (Carlos Pinheiro) Estática (Cansado de Carvalho) e Desenho (Fernando Conduto).

No $2^{\circ}$ ano, em Projeto o professor era foi o arquiteto Duarte Cabral de Mello, em Teoria da Arquitetura o arquiteto Michael Toussaint, e a Desenho o professor foi o Daciano Costa. No $3^{\circ}$ ano o arquiteto Guedes de Amorim foi o professor de projeto - que nos ensinava, sobretudo, como se construía - gostei essencialmente porque, com ele me apercebi dos diversos métodos construtivos e de como se montavam projetos. No $4^{\circ}$ ano o professor de projeto, foi o arquiteto Vítor Consiglieri, era o oposto do $3^{\circ}$ ano, a 
materialidade e o modo de construir não lhe interessava minimamente, no entanto, em termos de composição e harmonia do desenho as suas aulas eram fascinantes, e depois, na análise das nossas propostas era extremamente exigente.

Finalmente, $05^{\circ}$ ano, o professor era o arquiteto Troufa Real e o nosso querido Manuel Graça Dias (MGD) era o seu assistente. Foi uma alegria!

Foi o primeiro ano em que o MGD deu aulas em Arquitetura, foi um ano fantástico, introduziu uma dinâmica incrível, inacreditável mesmo, contagiava-nos a todos com o seu enorme sentido de humor e ao mesmo tempo, de critica e de perspicácia. Não estávamos habituados, em nenhum dos quatro anos anteriores se tinha passado nada parecido. Foi um ano fantástico com um professor fantástico!

\section{Durante o curso, foi tendo experiências em atelier?}

Sim, tive no atelier do meu pai, começou mais, como um trabalho de apoio, quase de secretariado, ia aos correios e tirava fotocópias/cópias heliográficas. No 3aa o comecei a fazer trabalhos de desenho. Havia uma grande estratificação, os arquitetos concebiam, depois os colaboradores desenhavam. Esse tempo ajudou-me muito no completar da formação, de como se montavam os projetos, de como eram as diversas fases, e de como se construía. Naquele atelier havia um grande gosto pelo detalhe, comecei a desenhar pormenorização, já me chegava definida, apenas a desenhava e montava nas folhas do projeto. Era um processo muito curioso, os desenhos não eram a tinta - ou melhor, os desenhos gerais, à escala 1:100 e 1:50 eram, mas tudo o que era detalhe, escala TN era desenhado a lápis. E eram uns desenhos incríveis, uma maneira de trabalhar muito interessante, tudo desenhado em vegetal, mas não em vegetal espesso nem naquilo a que chamamos de esquisso, era um papel de gramagem intermédia, com tudo desenhado a lápis, os desenhos ficavam lindíssimos, onde as nuances de intensidade da grafite eram fundamentais. Foi nesta altura que comecei a desenvolver o enorme gosto que tenho pelo detalhe e pela pormenorização.

Foi essa a única experiência que tive, depois, assim que terminei, passados uns dias, comecei a trabalhar com o MGD e com ele continuei até 2018.

\section{Manuel Graça Dias era o seu professor e, mal acabou o curso, convidou-o para trabalhar com ele?}

Sim, no final das apresentações, perguntou-me se eu tinha tempo, se estava disponível para colaborar num trabalho que ele estava a fazer, um loteamento em Chaves, a Quinta da Condeixa. Já devo ter feito mais uns quantos loteamentos pelo meio dos quais não me lembro, assim de repente do nome, mas deste nunca mais me esqueci.

Lembro-me de ter ido ter com ele, de me ter mostrado um desenho, uma rua serpenteante com uns blocos à volta, e me dizer "olha o loteamento é isto, é preciso 
cumprir estes índices, as volumetrias são estas e agora há que pôr isto de pé, eu tenho que me ir embora para a semana, para Chaves e daqui a 15 dias o Estudo Prévio tem de estar fechado, vai lá ter comigo com o trabalho pronto", portanto caí de para-quedas no trabalho e tive de me desenvencilhar, acho que consegui.... Lá fiz tudo o que tinha a fazer e levei os desenhos para Chaves.

Ir até Chaves, em 1985, era uma aventura de um dia, saíamos de Lisboa de manhã muito cedo e chegávamos a Chaves já de noite. O autocarro partia do Campo Grande, depois em Coimbra fazia-se um transbordo para outro autocarro, que ia até Vila Real e aí, mais outro transbordo para Chaves, tudo em estradas nacionais ondulantes e um tanto esburacadas. A ideia que hoje tenho de um país pequeno... naquela altura não a tinha, parecia-me era muito maior. Era tudo muito mais longe e levava tudo muito mais tempo. E foi este o primeiro trabalho que fiz com o MGD.

\section{E o atelier, nessa altura, qual era?}

O MGD não tinha atelier próprio, naquela altura, alugava uns estiradores no atelier do Manuel Vicente, na Travessa do Noronha. Aquela primeira reunião, do loteamento em Chaves, foi no atelier do Noronha. Depois de vir de Chaves, o trabalho continuou a ser desenvolvido e eu passei a trabalhar na Travessa de Noronha num dos estiradores do MGD. Na altura, trabalhavam lá, para além dos colaboradores, aqui em Lisboa, do Manuel Vicente (que na altura estava em Macau), o José Caldeira e o MGD que por sua vez tinha um colaborador, desenhador, o Raúl Andrade. Passou a ter-me a mim, também, como colaborador e lá fui trabalhando numa série de trabalhos.

A seguir surgiu a oportunidade de eu ir trabalhar, à noite, na Companhia de Teatro de Almada - Grupo de Campolide que, mais tarde, deixou cair a sua origem (Grupo de Campolide) e se tornou na companhia residente do Teatro Azul. Portanto, trabalhava no atelier do MGD durante o dia e à noite era o responsável gráfico e ainda o cenógrafo e figurinista residente da companhia, em Almada. No fundo, fazia de tudo o que havia para fazer na Companhia (graficamente falando), desde os cartazes, à paginação dos programas, a algumas cenografias e a alguns figurinos. Ficava lá até ao último cacilheiro sair para Lisboa, a companhia estava na Incrível Almadense, e ao fim da noite descia com o Joaquim Benite (diretor da companhia) e a Teresa Gafeira (actriz e mulher do Joaquim), a avenida até Cacilhas para apanharmos o último barco, salvo erro, à meianoite e vinte. No outro dia, voltava à mesma rotina, e por aí fora... até ser chamado para o serviço militar obrigatório, em Tavira, fazer a tropa. 


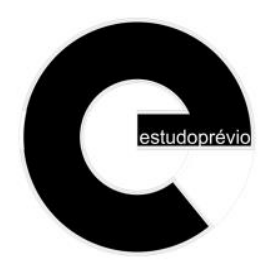

PT | E01 | EP18 | w2020

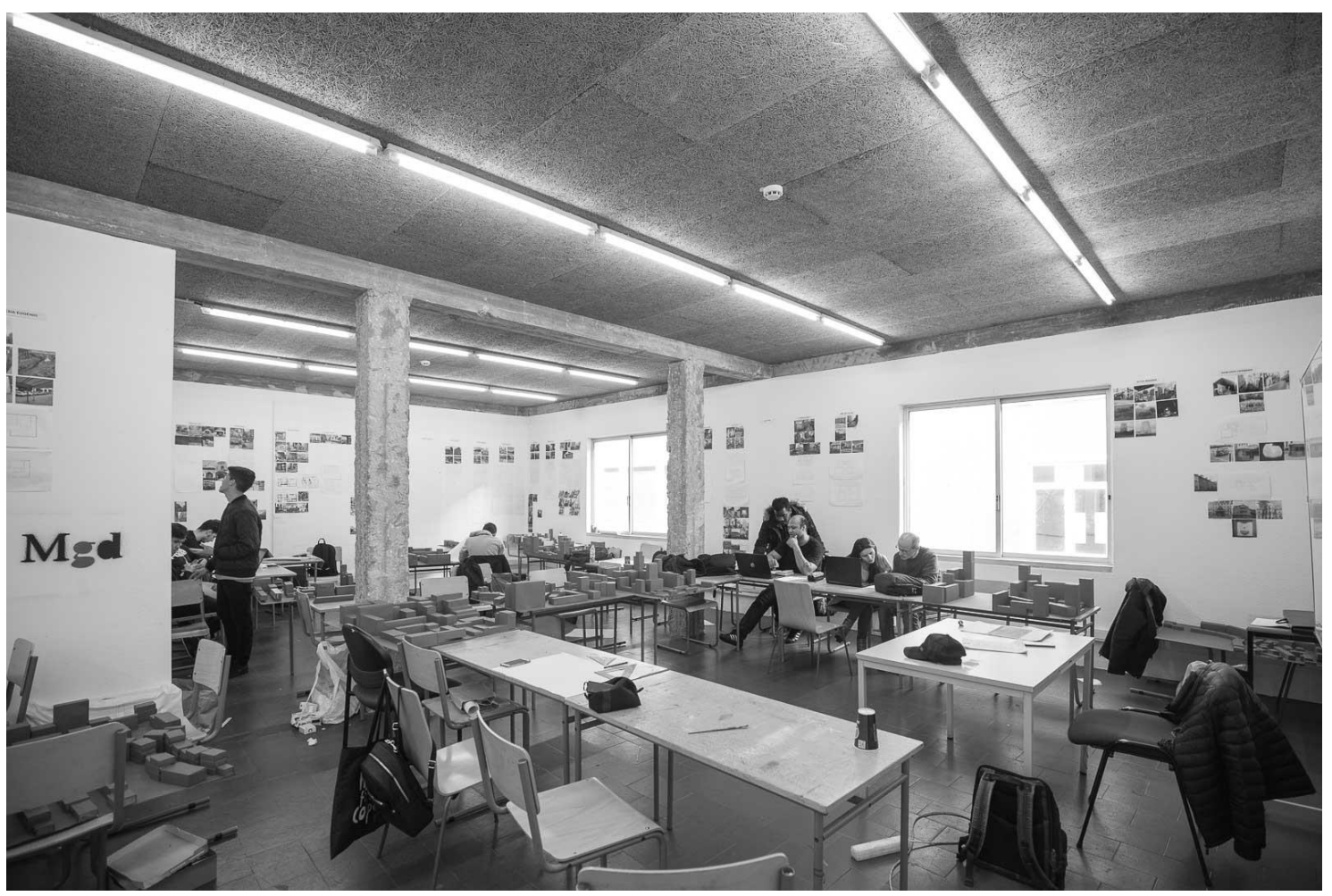

(c) Gonçalo Henriques + Estudo Prévio

\section{Fez alguns projetos na tropa?}

Sim, fiz alguns projetos, fiz um posto de vigia em Tancos - não deve ter sido grande coisa, porque foi para o mesmo local onde roubaram as armas! - Fiz uma sala para soldados, em Elvas, uma cantina e uma lavandaria em Estremoz e, já em Lisboa, fiz a adaptação de um edifício para a Direção dos Serviços de Saúde, em Benfica, num quartel junto ao Califa. E assim passaram os dois anos que estive no exército, no Serviço de Fortificações e Obras.

Durante esse tempo continuei a trabalhar com o MGD embora no princípio à distância, pois fui colocado em Évora, não havia vagas em Lisboa. Em Évora, no SFOE (Serviço de Fortificações e Obras do Exército) tínhamos um grupo simpático, funcionava como um pequeno atelier, um arquiteto (eu), um engenheiro civil, um engenheiro eletrotécnico, um engenheiro mecânico e um engenheiro de hidráulica. Depois, quando vim para Lisboa, já havia muitos arquitetos, uns do quadro, do exército e outros, cinco ou seis, do serviço militar obrigatório como eu. Cada um desenvolvia os projetos que lhe eram atribuídos, sempre supervisionados pelos arquitetos mais antigos, do quadro. Foi engraçado porque o trabalho dos Serviços de Saúde, ainda estava a decorrer, quando acabei o tempo do serviço militar e eles propuseram-me um contrato de prestação de serviços, para acabar o projeto. Foi o meu primeiro trabalho, enquanto profissional independente. 
Entretanto, o MGD saiu da Travessa do Noronha e foi, com o João Luís Carrilho da Graça, para a Calçada Marquês de Abrantes. O João Luís tinha alugado um espaço grande - que foi até há pouco tempo o atelier dele - e dividiu-o em três. A zona da entrada ficou para o MGD, a parte do meio ficou o João Luís com ela, e a última para o Carlos Manuel Dias. Eu dividi com o MGD a parte dele, porque tinha esse trabalho da tropa e uma série de outros pequenos trabalhos que, entretanto, tinha angariado. Fiquei com a cozinha e o MGD com as salas da frente. Dividíamos o espaço, mas continuei a trabalhar com o MGD, coordenava alguns projetos, e ao mesmo tempo fazia os meus. Entretanto, o MGD começou a dar-me coautoria dos trabalhos e fizemos alguns concursos juntos. Quando ganhámos Sevilha resolvemos fazer sociedade, e assim nasce o atelier Contemporânea.

Hoje em dia, estamos habituados a nomes de coletivos, mas naqueles anos, não era nada usual, existiam poucas sociedades de arquitetos, sobretudo que durassem para além do tempo de um ou outro trabalho. Para nós não, foi algo transversal à quase totalidade do nosso percurso de arquitetos, embora o MGD já tivesse mais dez anos de trabalho, com diversas colaborações, Manuel Vicente, António Marques Miguel, João Vieira Caldas, José Manuel Fernandes, mas nunca tinha tido uma relação tão estável, durante tantos anos, com a mesma pessoa, mantivemo-nos juntos até 2018 , até à sua morte.

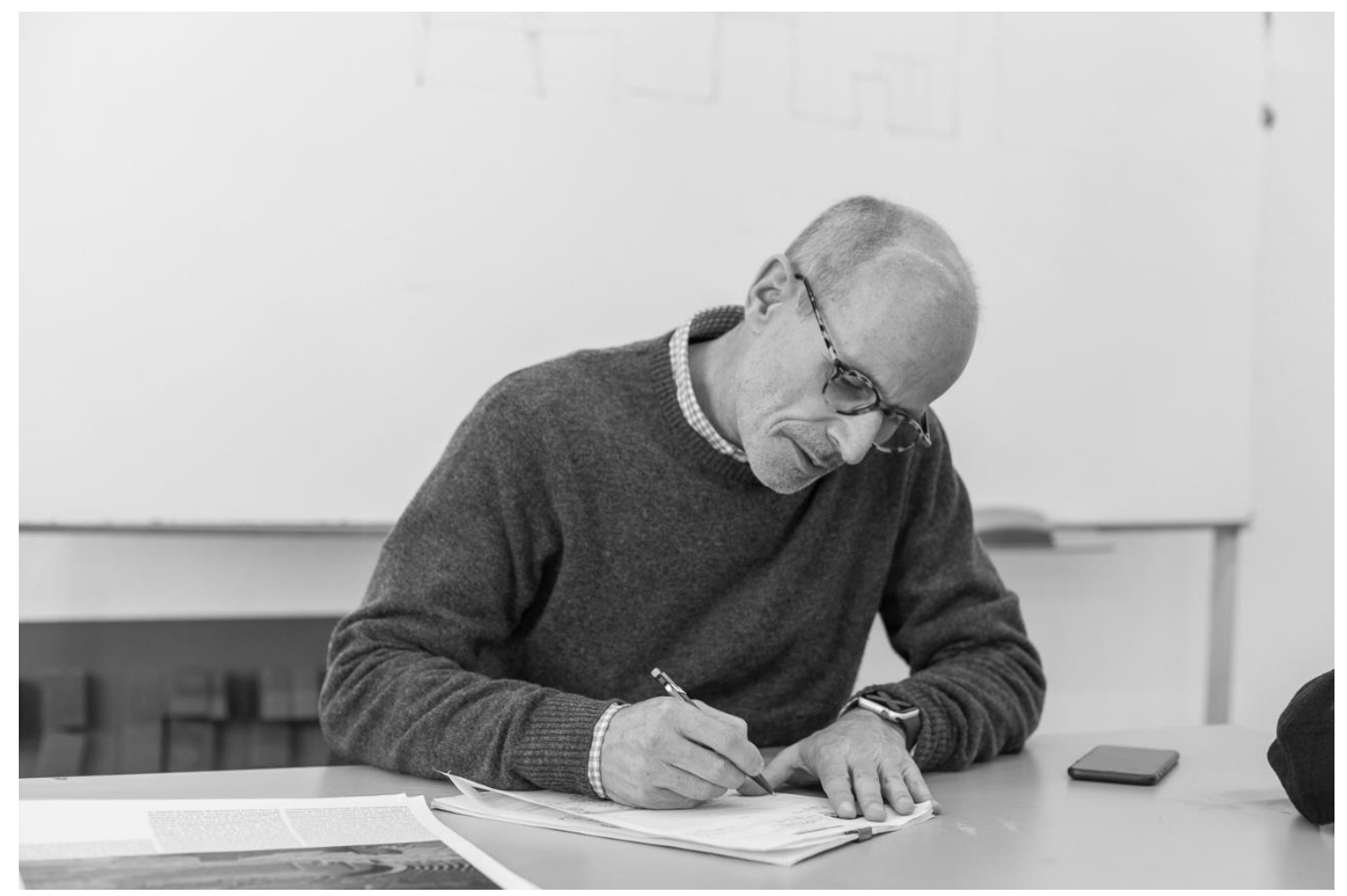

(c) Gonçalo Henriques + Estudo Prévio 


\section{Foi essa ideia da colaboração e da divisão de esforços que alavancou o vosso atelier? Até que ponto essa interação criou uma cultura diferente?}

Quanto a mim, uma das grandes vantagens da Arquitetura, quando comparada com outras atividades artísticas é não ser um trabalho solitário. Gosto de contar uma história, que se passou com a minha sobrinha Madalena Vidigal, quando ela, antes de ir para a Faculdade de Arquitetura no Porto, trabalhou no atelier da minha irmã - Ana Vidigal, pintora - como sua assistente, um dia vai o atelier do meu irmão - Nuno Vidigal, arquiteto - fica fascinada e diz "Isto é muito melhor do que ser artista plástico, não estamos sozinhos, fala-se muito mais, existem outras pessoas com quem partilhar ideias, não há a solidão da decisão, é muito melhor!"

De facto, é assim mesmo. Em Arquitetura não temos essa solidão. Pelo menos eu nunca a senti, agora sinto um bocado, o MGD já cá não está. Mas, quando estávamos os dois, sabíamos que havia uma série de tarefas que estavam quase garantidas, eu fazia "isto", o MGD fazia "aquilo", quando tínhamos dúvidas, falávamos e as coisas fluíam, muito melhor do que estar solitariamente a decidir, sem ter ninguém com quem dialogar. No fundo ele confiava plenamente na minha opinião e eu na dele.

Quando há outra pessoa com quem trabalhamos e com quem conseguimos dialogar, torna-se tudo muito mais interessante. Gosto bastante de trabalhar em equipa. Habitueime sempre a trabalhar com outras pessoas, raramente tive trabalhos sozinho. É sempre muito mais interessante estar acompanhado a trabalhar do que estar sozinho, no meu caso, isto até um tanto contraditório com o meu modo de ser, pois na minha vida não profissional, na vida pessoal, aprecio bastante o anonimato e raramente o partilho.

\section{Esta forma de trabalhar em colaboração, de ter vários colegas que discutem projeto, também passou para a UAL? A estrutura do curso sempre teve a ideia de ter um atelier onde os alunos se reúnem e estão todos juntos.}

Essa ideia de colaboração não é nada que tenha sido descoberto pelo MGD ou muito menos, por mim! É claro que é fundamental e o MGD bateu-se bastante na UAL para que ela existisse. Para os alunos do $1^{\circ}$ ano, sobretudo, o convívio com os alunos mais velhos é fundamental, são experiências trocadas e que geram massa critica, geram opinião, geram crescimento.

É muito importante que haja um atelier transversal a todos os anos, como o que existia na UAL da Boavista, e que agora se está também a reimplementar em Campo de Ourique, era uma sala fundamental, os alunos encontravam-se ali todos a trabalhar, como se estivessem num atelier, discutindo desenhos, amparando-se uns aos outros e gerando o diálogo, fundamental para a sedimentação e consolidação de ideias. 
Há alguma relação entre o atelier e a escola? Eu (João Caria) e o Carlos (Sequeira) fomos convidados, ainda no $2^{\circ} a n o$, a ir ao vosso atelier, na Rua Dom Dinis, e essa experiência foi fundamental para perceber o que era um atelier. Lembro-me que sempre foi usual convidar alunos para passarem pelo atelier.

Sim, e isso continua, ainda existe essa vontade, neste momento, temos no atelier um aluno da UAL, a trabalhar num concurso, está lá como se de um estágio se tratasse, a perceber como funciona um atelier, como se monta e se põe de pé um projeto. Penso que será sempre desejável que aconteça, por vezes, nem sempre é possível, mas nós, professores, deveremos esforçarmo-nos mais para proporcionarmos essa experiência aos alunos da UAL.

\section{E o contrário? Há experiências ou investigações que começam no atelier e que acabam por transbordar para a escola?}

Acredito que eventualmente possam acontecer em anos mais avançados, mas, no meu caso, o $1^{\circ}$ ano dificilmente existe. A UAL tem tido uma série de alunos oriundos, a maior parte deles, do Brasil e de Angola, que não conhecem Lisboa. O1ํ ano é sobretudo para os alunos terem a noção da cidade onde vivem, de como é que a cidade evoluiu, as suas origens, como ela chegou até hoje. A maioria do trabalho desenvolvido está relacionado com a cidade de Lisboa.

O modelo que temos para o $1^{\circ}$ ano é baseado no conhecimento da cidade e, numa segunda fase, no desenvolvimento das capacidades plásticas e na desconstrução dos complexos que se tem na expressão plástica. O João Quintela, em Desenho, dá-nos uma ajuda muito grande, com os exercícios que faz com eles. Tentamos que perceberem que não há "maneiras certas de fazer". Gostamos de lhes incutir o espírito de que não há apenas um único caminho, há muitos caminhos para se chegar a qualquer lado.

Prefiro que eles esqueçam e que façam uma espécie de reset da aculturação que tiveram desde que começaram a ter consciência do que era desenhar, que se libertem dos complexos a que a aculturação os levou. Nas aulas de Desenho ouço imensas vezes frases do tipo "Ah, eu não sei desenhar!" "Não sou capaz de desenhar uma pessoa!" "Não tenho jeito para desenhar". É evidente que toda a gente é capaz de desenhar, e é capaz de desenhar uma pessoa independentemente do "jeito" que tem ou não tem. Precisam é de se libertar dos complexos que lhes foram sendo incutidos ao longo dos anos, que nos apontaram como a maneira certa de fazer. Os alunos chegam ao $1^{\circ}$ ano - provavelmente porque não tiveram professores de desenho, ou outros professores, suficientemente interessantes - e não se apercebem de que há muitas maneiras de se exprimirem. Acho importante descomplicar essa incapacidade e angústia que os alunos têm em "fazer". Também, aquela ideia de um ensino, que vem das Belas-Artes, em que há um mestre e que o aluno se vai desenvolvendo por cópia do mestre, a fazer "à maneira de" e só então depois, eventualmente, ganha alguma autonomia, sinceramente, não acredito muito nela. 


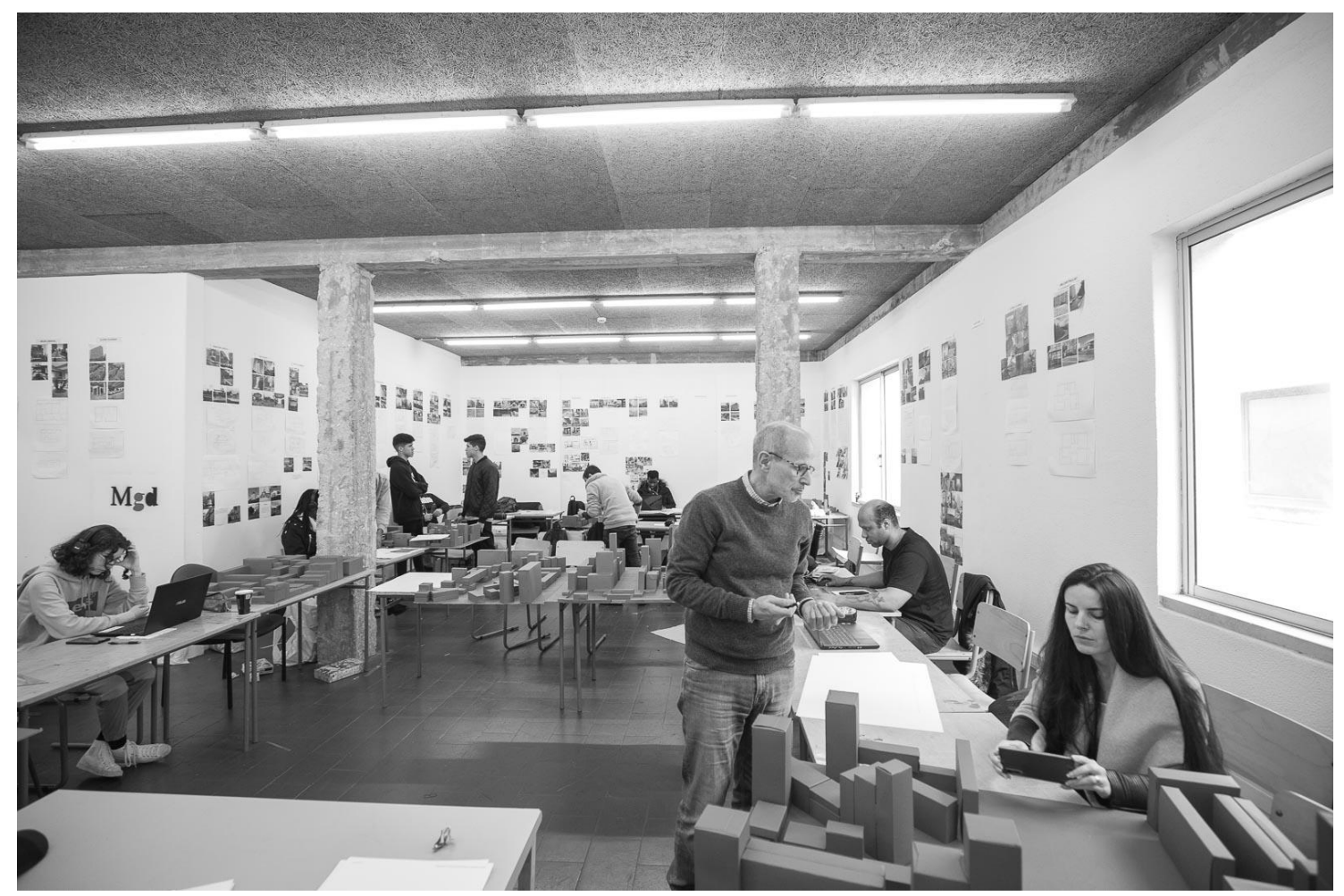

(c) Gonçalo Henriques + Estudo Prévio

Olhando para a minha experiência como vosso aluno, lembro-me de que o que levei do meu $1^{\circ}$ ano foi essa liberdade e descomplicação de olhar 0 mundo e de conseguir expressar-me com os meios que tenho. E sempre vi o atelier Contemporânea como uma lufada de ar fresco de liberdade, fora do mainstream da arquitetura portuguesa.

Não acho que haja uma só maneira de fazer e também não vejo as coisas tão negativamente, não acho que estejamos em perigo de estarmos a fazer todos da mesma maneira. Para mim, as abordagens são sempre diferentes, o pior que me podem fazer é dizerem-me para fazer o que eu quiser. Eu não quero fazer nada! Quero ajudar a resolver problemas e tentar apontar caminhos de que eventualmente não se estaria à espera, sempre com o intuito de resolver um determinado problema, sinceramente não sei se somos fora do mainstream, mas é a nosso modo de trabalhar.

Penso que a abordagem que nos descrevia traz consigo a ideia de heterogeneidade.

Exatamente! Mas, às vezes, a heterogeneidade também pode ser perigosa. Porque uma coisa é nós termos o à vontade de não renegarmos "à partida uma ciência que desconhecemos". Portanto, vamos experimentar e explorar as mais-valias que potencialmente possam existir. Essa é a maneira que o MGD me ensinou a abordar a 
Arquitetura e é essa a maneira como eu gosto de a fazer. Gosto da ideia de ter essa variedade e essa disponibilidade para desenvolver o trabalho. No ensino, também percebo a necessidade de existir um controle, por parte do professor, para refrear algumas dessas "espontaneidades" porque, se não forem assertivamente controladas, podem levar à ideia de que vale tudo! E não vale tudo.

\section{Como é que vê a Arquitetura que se faz hoje e as condições de trabalho atuais?}

Ao longo destes anos, em que tenho feito arquitetura (comecei em meados dos anos 80 ), assisti a diversos modos de comunicar o projeto. Primeiro, desenhava-se a tinta da china sobre papel vegetal e as cópias eram heliográficas. Depois começou-se a utilizar o computador, a impressão já em plotter's, ainda era feita com canetas de tinta da china sobre peliculas, a reprodução, no entanto, ainda era heliográfica. Mais tarde apareceram as plotters de jacto de tinta, depois a modelação 3D e os renderings e, agora, estamos a dar o passo para trabalhar em BIM (Building Information Modeling). São maneiras muito diferentes de encarar a produção do desenho que é necessário para comunicar a arquitetura. Não é para fazer Arquitetura. A maneira de fazer Arquitetura é exatamente a mesma.

Por exemplo, há uns anos quando ainda se datilografava, quando nos enganávamos, tirávamos a folha e tínhamos de escrever tudo outra vez. Depois, começou a haver uma fita branca que se colocava sobre o texto e voltava-se a escrever por cima. Depois veio - Word e tornou tudo mais fácil. Isto é, houve uma enorme evolução e um grande encurtar do tempo necessário para "passar um texto à máquina", não para o escrever. Há um trabalho anterior, uma reflexão que é preciso fazer para se escrever um texto, e isso representa tempo, que não o tempo do "passar o texto à máquina".

O mesmo se passa com a produção do desenho, está mais rápida e o facto de a tecnologia ser realmente super eficaz, leva a que se julgue que o tempo para fazer é muito mais curto. Mas esse tempo é exatamente igual, porque a maturação de um projeto, do definir das suas premissas, é exatamente o mesmo. A sua produção é que é mais rápida. Isso levou ao enorme problema que temos hoje em dia - a falta de tempo para a reflexão. Quem consegue fazer projetos, nos prazos que os clientes nos dão para fazer? Tenho uma profunda admiração por quem o consegue, de uma maneira honesta e eficaz, porque eu não consigo. Sinceramente acho que os processos têm um tempo próprio, têm de levar o seu tempo. O tempo de projeto não é apenas o tempo que é necessário para o comunicar, isso é uma outra fase. O tempo de fazer o projeto, hoje, é incrivelmente curto. Os renders também são perniciosos, porque rapidamente se faz uma modelação de qualquer coisa e fica-se com uma imagem muito charmosa do que uma qualquer coisa possa ser. Essa imagem faz-se, mas com essa imagem não se faz nada! Muitas vezes essas imagens não resultam de uma síntese espacial consubstanciada em plantas e em cortes... São uma espécie de Pinterest espacial, de uma cartilha do gosto. Outro "perigo" dessas imagens é os clientes, as entidades que escolhem os projetos, por uma questão de facilidade, terem muito mais tendência em olhar para as imagens do que em analisar os desenhos. 


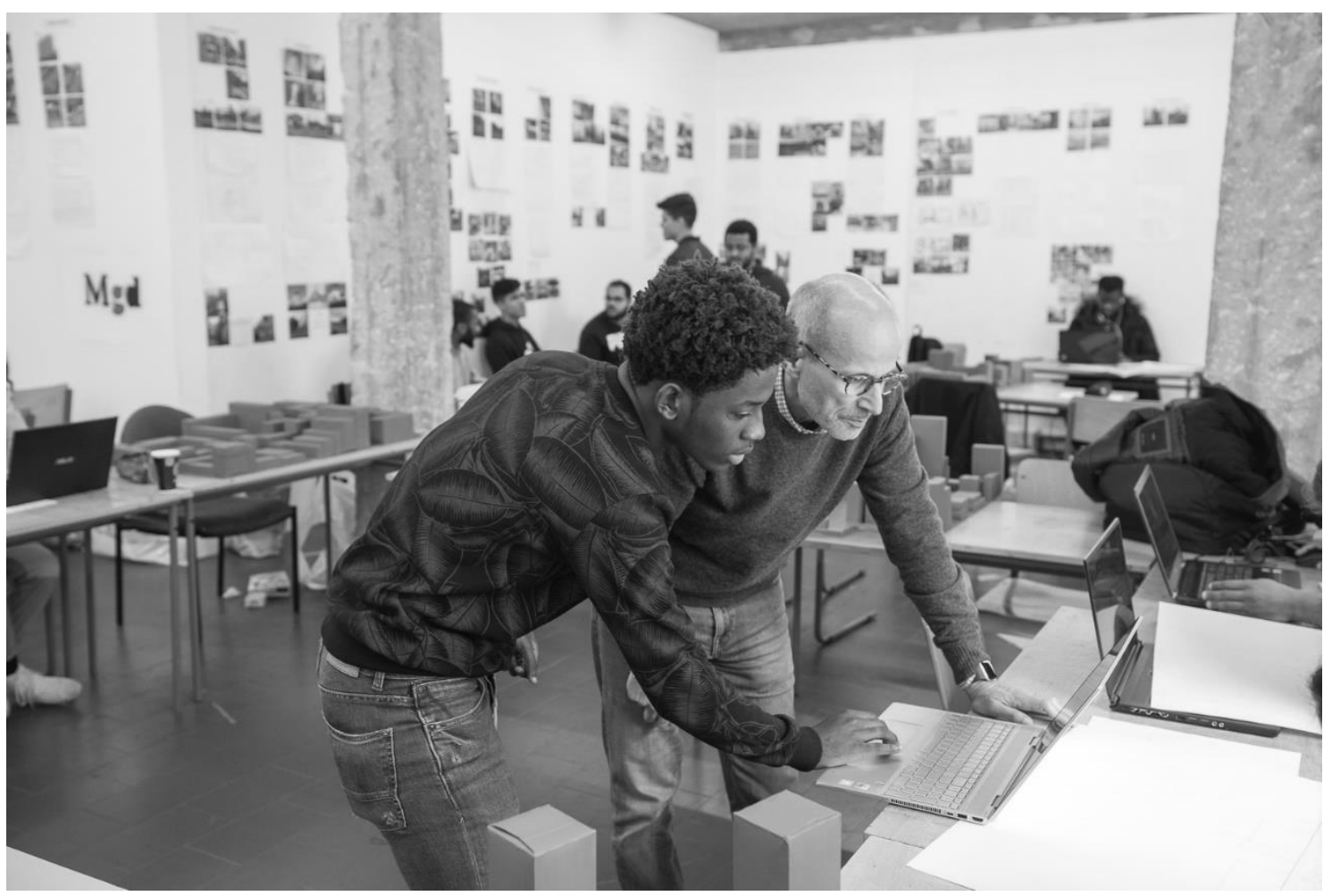

(c) Gonçalo Henriques + Estudo Prévio

Ainda outro dia, num júri de um concurso, dei comigo a olhar em primeiro lugar para os renders. Tive de me esforçar, esquecer as imagens e ir ver as plantas, as relações que se estabeleciam, os cortes e os alçados. A espacialidade não se capta numa imagem $3 D$, ela é uma manipulação que, eventualmente, representa o que se está a fazer. $A$ espacialidade capta-se na leitura das plantas e dos cortes. Essa análise perdeu-se, ninguém tenta ler plantas e cortes. Agora olha-se para uma imagem e diz-se se é bonita ou feia, se tem cores bonitas ou não, se as texturas resultam, se as formas são elegantes ou não...

\section{No fundo a Arquitetura é o espaço, não é 2D.}

Sim, é isso. Se fosse assim, o Convento de São Francisco nunca passaria de Convento a Biblioteca Pública, depois a Escola de Belas Artes. A capacidade que aquele edifício tem em se transformar, deriva da sua extraordinária espacialidade. A capacidade de um edifício não resulta do que lá se passa, mas sim da sua espacialidade, naquelas celas tanto faz que se durma ou acumule livros ou se ensine, também tanto faz se são amarelas ou verdes. É tinta. O importante é perceber se o espaço é, ou não é interessante. 


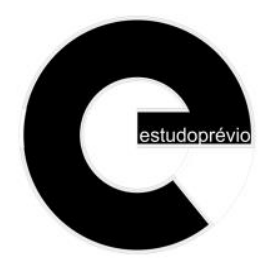

PT | E01 | EP18 | w2020

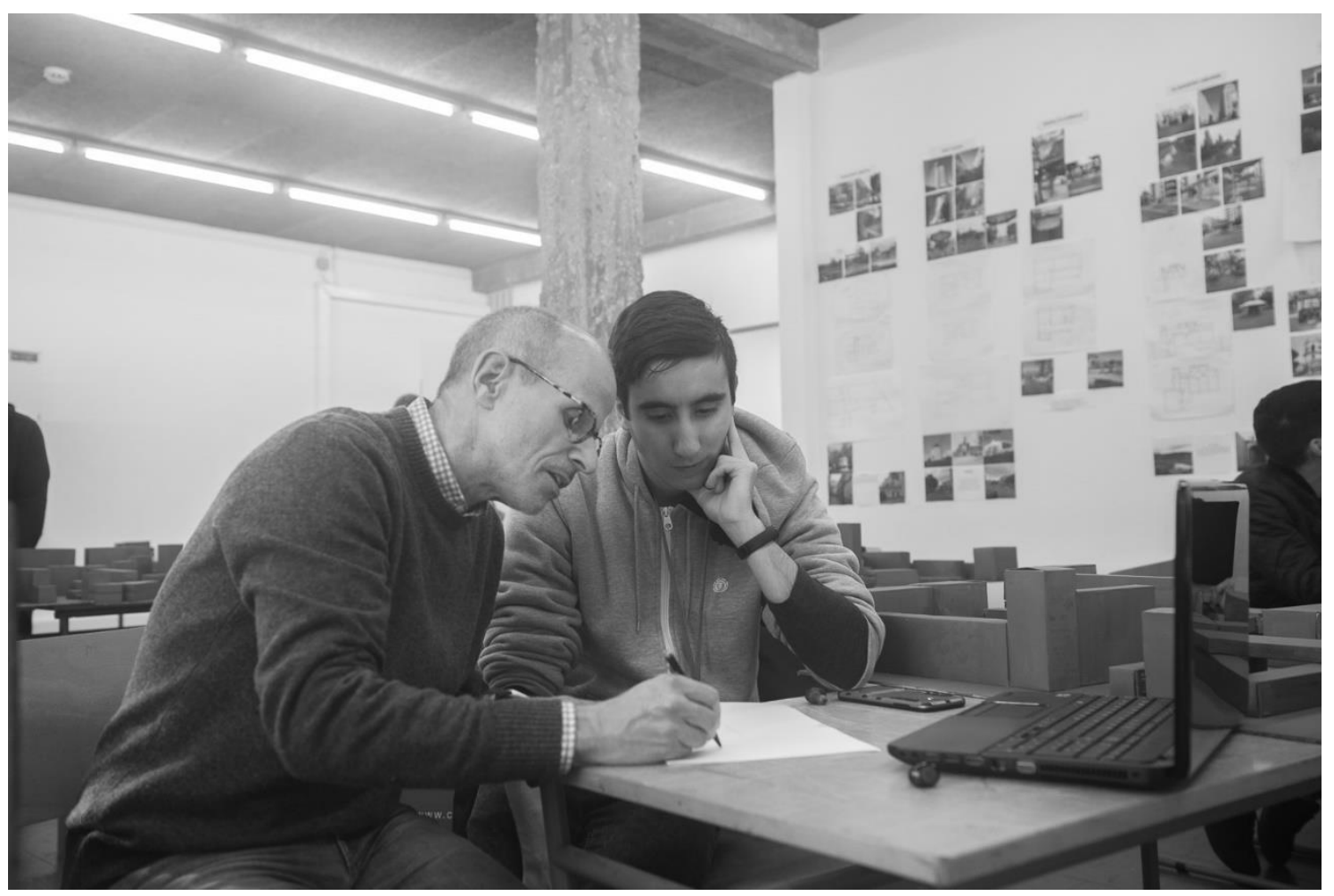

(c) Gonçalo Henriques + Estudo Prévio

\section{Tem alguma mensagem para os alunos de arquitetura?}

É uma profissão maravilhosa! É certo que é difícil e está cada vez mais difícil o acesso ao trabalho, somos cada vez mais, mas é realmente maravilhosa, se o não fosse, não estaria aqui, ao fim de quase quarenta anos, entusiasmado, a falar dela.

É preciso alguma persistência e vontade de fazer, mas consegue-se. Hoje ser-se arquiteto não é só fazer arquitetura, também é fazer critica de arquitetura, é escrever, é refletir, são muitas as valências que concorrem para esta profissão.

Lembro-me de que quando andava na escola, me assustei imenso quando me apercebi que, por exemplo os italianos, a grande maioria deles não fazia arquitetura, fazia outras coisas, e isso nunca me tinha passado pela cabeça... Hoje já me faz algum sentido, sobretudo pela capacidade que os cursos de arquitetura tiveram em se reinventar e criar outros caminhos para os arquitetos que saem, tenhamos vontade e gostemos de fazer. 